\title{
Distance Learning at University From A Lifelong Learning Perspective
}

\author{
Genute Gedviliene, (Dr., Professor) \\ Vytautas Magnus University, Lithuania \\ Vilhelmina Vaiciuniene (Dr., Assoc. professor) \\ Mykolas Romeris University, Lithuania
}

doi: 10.19044/esj.2016.v12n34p46 URL:http://dx.doi.org/10.19044/esj.2016.v12n34p46

\begin{abstract}
The paper discusses the importance of distance learning within university education. This issue stems from lifelong learning perspective, relating to social factors as emigration, demographic situation and competitiveness in the labour market. Distance learning is one of the possible solutions to acquire education to working people or those who live in remote locations. The main focus of our research was on learning quality and students' satisfaction based on the case study of distance learning mode application. The research sample was composed of 126 part-time students who participated in the distance course organized as a part of university education. The case study of a distance course presented in this paper and survey findings revealed the study participants' positive approach to distance learning in the university educational process. New technologies and their resulting opportunities for learners to interact with each other and with teachers, provision of guidance and logically structured material created preconditions for students' satisfaction. Therefore, we assume that development of distance learning courses, constructivist learning environment with its inherent creative approach to learning provision can bring solutions to many social and educational issues, such as big emigration flows of young population, better employment opportunities and selfrealisation of young adults.
\end{abstract}

Keywords: Distance learning, lifelong learning, university studies, evaluation of distance course

\section{Introduction}

The increasing flow of information, rapid technological, social and cultural changes determine new trends in adult education. Higher education institutions are open to meet the needs of the present society. This is 
particularly relevant in Lithuania today due to decreasing demographic situation, great emigration flows, young persons in particular, changes in the labour market. Higher education institutions are searching for solutions how to attract young adults who live and work abroad to study at their homeland universities. Distance learning offers such opportunities for persons who seek education but live far away from their home. Distance learning being one of the possible solutions has been extensively discussed among researchers and education policy makers in Lithuania. In many countries worldwide distance learning is perceived as a separate didactic system (Teresevičienè et al., 2004). Yet, in Lithuania today distance studies are understood as a learning method, which can be used as a constituent component of university studies or as an independent course unit. Present experience manifests that institutions of higher education are competent to implement distance teaching/learning as a didactic system into the Lithuanian adult learning system. Thus, this academic adult learning trend is reflected in the engagement of Lithuanian education institutions in competitive high-level education provision and scientific polemics. Distance learning has many advantages over traditional academic studies. First of all, the emphasis in distance education is on information technology that provides excellent information retrieval, processing, storage and dissemination capabilities necessary for meaningful and deep learning studies. Secondly, distance teaching can be incorporated in university practice and become a major factor for further development of a higher education institution. The aim of paper is to reveal the necessity of distance learning within higher education institution. The main focus of the research is on the learning quality and students' satisfaction based on the case of distance learning mode application. The research sample was composed of 126 respondents, adult part-time students, who participated in the distance course. The following research methods were applied: a) descriptive analysis of the distance course; 2) qualitative analysis of findings obtained through a survey of the study participants.

\section{Distance studies as a new learning opportunity}

Although research and discussions about distance learning as a recent phenomenon have emerged in the latest decades, it actually dates back over 120 years (The Guardian).

Traditional teaching and learning approaches are insufficient to fulfil the expectations of today's learners (Rikala et al, 2014). Modern distance learning initially relied on the development of postal services in the 19th century. The next step was The Open University in UK (1969), which initially relied on radio and television broadcasts for much of its delivery. 
Honeyman and Miller (1993) defined Distance education as: “< $<$. > is a field of education that focuses on teaching methods and technology with the aim of delivering teaching, often on an individual basis, to students who are not physically present in a traditional educational setting such as a classroom”. (Honeyman and Miller, 1993, p. 67). According to Rikala et al (2014) traditional teaching and learning approaches are insufficient to fulfil the expectations of today's learners. Distance learning, e-learning, online learning, virtual or mobile learning opportunities have been widely discussed as an alternative to traditional teaching and learning in the recent decades. Rikala (2015) analyses the interrelationship and differences between elearning, distance learning and mobile learning. The author emphasises differences in time and space and views technology as a tool to bridge the differences and gaps using the pace of study and methods convenient for students.

The European Commission in most of its documents on education stresses the importance of lifelong learning not only for competitiveness and employability, but also for social inclusion, active citizenship and personal development. Thus, in order to stay competetive in ever changing labour market adult learners need a set of skills that may be attained via holistic and lifelong learning (Teresevičienè et al, 2004). "When it comes to distance learning, the people who are more likely to utilize it are working professionals who are seeking to upgrade their skills, achieve additional certification or a higher degree" (The International Association for Distance Learning). There are also students who live at a distance from an education institution. Adults are constantly encouraged to grow and develop through formal, non-formal and informal learning opportunities, mastering their ability to know (the development of intellectual maturity), the ability to do (to promote student motivation), the ability to be active participant (public spiritedness of developing skills) and the ability to live together (in order to effectively collaborate). The changes in adult education embracing the components of adult learning through life are reflected in Figure 1. 


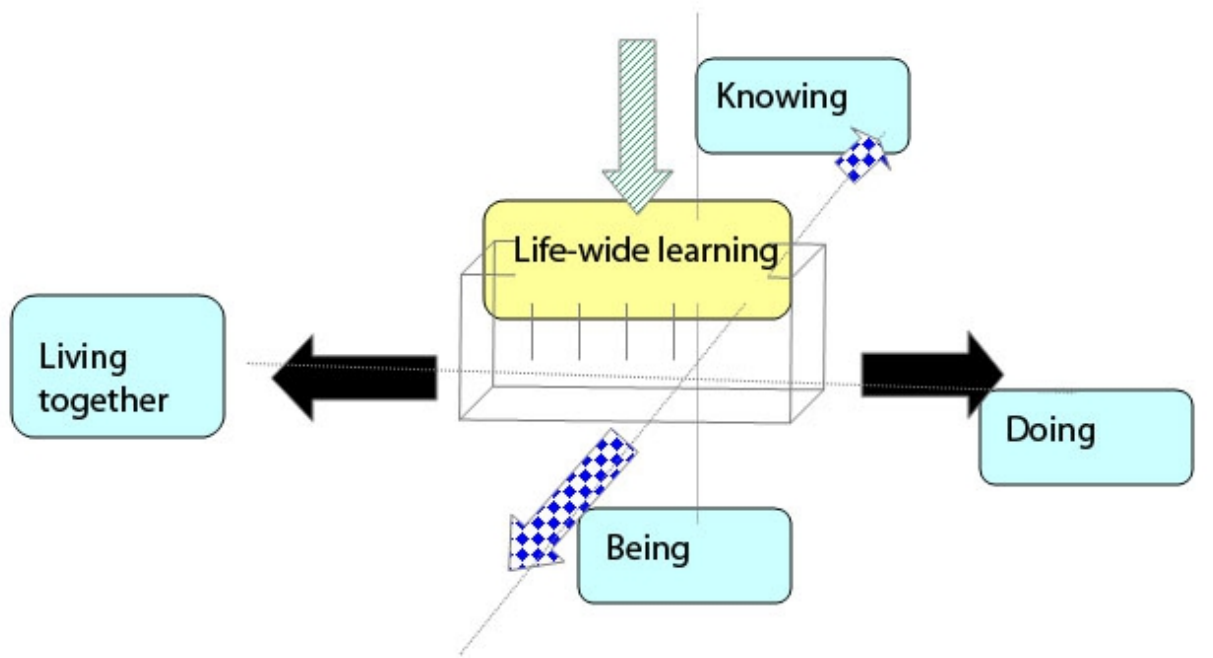

Figure 2. Changes in life-wide adult education

Successful implementation of the objectives of Lifelong Learning Memorandum (2000) and Lisbon Strategy (2001) is due to perspectives and opportunities offered by distance learning. Distance studies are becoming a method and form of studies, and they properly respond to the predominant learner perspective and distance learning fits to our day life tendencies and requirements to improve and learn lifelong (Nuissl et al 2008).

The European Commission identified flexibility and quality in course offerings as distance learning factors of utmost importance (EC Press Release Database). However, the lack of quality in adult education provision in relation to the presentation of information, needs analysis, demands of training services, educational support, evaluation methods, knowledge and skills recognition, validation and certification has been reflected by low level of educational outcomes. Teaching/learning methods and materials should be developed, taking into account the specific needs and attitude of adults. It is necessary to define learning outcomes, provide students access to learning support, for example the necessary training skills development.

Another important factor stressed by the $\mathrm{EU}$ is ,... widening of access to higher education for broader sections of the population, including working adults and less favoured groups in society, is a policy objective in all Member States.” This factor is especially relevant to Lithuania, whose citizens are scattered around the world, most of them being young adults who did not have appropriate opportunities to acquire higher education. If we want to encourage adults to participate in inclusive learning, it is necessary to improve the quality of learning and if we want to provide a flexible, affordable and quality adult learning opportunity, one of the most 
appropriate forms of studies is distance learning. Rapid technological development, abundance of various formats and sources of information determine the need for distance learning, as information, knowledge and skills in today's information society are of particular value. Moreover, inexorable pace of life increases at an enormous speed, the majority of working people who wish to upgrade their skills or acquire a different profession do not have a possibility to retreat from their everyday work and study at a university. Thus, distance education/learning is an alternative solution. Distance learning is gaining its popularity in Lithuania, at university in particular. According to Rutkauskienè et al. (2007), distance learning is interaction between teacher, student and technical means of information necessary for such interaction to develop and maintain. Furthermore, in the case of distance learning a bigger part of the learning process management and control depends on a student. Asynchronous or indirect communication between the teacher and student is based on modern ICT literacy, helps to reconcile the wish of improvement creating opportunities for self-study at your convenience, chosen location and study load. This flexible form of study is primarily designed for busy working people who wish to upgrade their qualifications. Moreover, it is an acceptable learning form to the unemployed and socially excluded people.

In distance learning new information technologies and communication and collaboration tools are very important: the ability to work in a virtual system, the analysis of prepared material and tracking of tasks to be assigned, participating in chats and discussion forums, virtual learning environments, audio and video conferences.

There is a big variety of approaches to distance learning and clarification of the concept. As Vermeersch states "distance learning is wellfounded relation by dialogue, structure and autonomy, which is necessary the technical mediatorial measures” (Vermeersch, 2008, p. 9). According to Rutkauskienè et al (2007) distance learning is the delivery form of knowledge, skills, attitudes, by applying ICT used by students to study in different places at the same time. Nuissl et al (2008) consider that distance learning is a form of learning when learners are physically separated from the teacher. Such separation can be applied to the whole learning process or through a mixed principle, for example, only some of the learning stages. Shachar and Neumann (2010) grounding on other researchers have researched the differences between traditional and distance learning and state that: "The transformation from the traditional Face-to-Face (FTF) classroom mode to new delivery methods and platforms (correspondence, Internetonline, one-way, two-way audio and video) collectively known as Distance Education (DE), led some experts so far as to predict that the 'residential based model,' that is, students attending classes at prearranged times and 
locations, will disappear in the near future” (Shachar and Neumann, 2010, p. 318).

Creation of a distance-learning course is based on the conceptual provisions of a dialogue, structure and autonomy. Dialogue is based on the humanist provision, relates to students' interaction, assuming that success of learning implying improvement of students' reasoning, discussion, critical thinking skills is possible through active participation in dialogue. The principle of structure is related to detailed planning, a calendar systematic filling, time-fixing and control. As Rutkauskienè et al (2007) consider, the principle of autonomy encourages independent decision making, students' creativity performance in a virtual learning environment.

\section{Discussion of the results}

In pursue to reveal the nature of distance studies and define the quality of learning, the research on the distance learning course "Adult learning in distance studies” and students’ feedback was conducted.

\section{Methodology}

The research is based on constructivist and experiential learning methodology. The key assumptions underlying the theory argue that social and experience-based practice creates preconditions for changes in human thinking and behaviour. The relevance of the theories for the research stems from the idea that they reveal adults' abilities to adapt to learning innovations, experience-based practicality and diversity (Fenwick, 2003).

The distance course "Adult learning in distance studies" within the Learning Management Services programme started in autumn 2014 at Vytautas Magnus University, Faculty of Social Sciences, Department of Education. In the preparation phase of the distance course the major attention was given to the following methodological aspects: the pre-preparation, access to learning, learning objectives, methods, and evaluation components of the consistency of the teacher preparation, planning, teacher competence and skills, learning instruments, communication and cooperation skills (Rutkauskienè et al, 2007). The value and quality of the course "Adult learning in distance studies" was assessed by conducting a quantitative study. Students' feedback on the course was applied via a questionnaire survey. The survey involved 126 distance students who expressed their opinion about the course content and their experience acquired during the distance learning course.

Successful implementation of the objectives of Lifelong Learning Memorandum (2000) and Lisbon Strategy (2001) is due to perspectives and opportunities offered by distance learning. Distance studies are becoming a method and form of studies, and they properly respond to the predominant 
learner perspective and distance learning fits to our day life tendencies and requirements to improve and learn lifelong (Nuissl et al, 2008).

The European Commission identified flexibility and quality in course offerings as distance learning factors of utmost importance (EC Press Release Database). However, the lack of quality in adult education provision in relation to the presentation of information, needs analysis, demands of training services, educational support, evaluation methods, knowledge and skills recognition, validation and certification has been reflected by low level of educational outcomes. Teaching/learning methods and materials should be developed, taking into account the specific needs and attitude of adults. It is necessary to define learning outcomes, provide students access to learning support, for example the necessary training skills development.

Another important factor stressed by the EU is „... widening of access to higher education for broader sections of the population, including working adults and less favoured groups in society, is a policy objective in all Member States." This factor is especially relevant to Lithuania, whose citizens are scattered around the world, most of them being young adults who did not have appropriate opportunities to acquire higher education. If we want to encourage adults to participate in inclusive learning, it is necessary to improve the quality of learning and if we want to provide a flexible, affordable and quality adult learning opportunity, one of the most appropriate forms of studies is distance learning. Rapid technological development, abundance of various formats and sources of information determine the need for distance learning, as information, knowledge and skills in today's information society are of particular value. Moreover, inexorable pace of life increases at an enormous speed, the majority of working people who wish to upgrade their skills or acquire a different profession do not have a possibility to retreat from their everyday work and study at a university. Thus, distance education/learning is an alternative solution. Distance learning is gaining its popularity in Lithuania, at university in particular. According to Rutkauskienè et al. (2007), distance learning is interaction between teacher, student and technical means of information necessary for such interaction to develop and maintain. Furthermore, in the case of distance learning a bigger part of the learning process management and control depends on a student. Asynchronous or indirect communication between the teacher and student is based on modern ICT literacy, helps to reconcile the wish of improvement creating opportunities for self-study at your convenience, chosen location and study load. This flexible form of study is primarily designed for busy working people who wish to upgrade their qualifications. Moreover, it is an acceptable learning form to the unemployed and socially excluded people. 
In distance learning new information technologies and communication and collaboration tools are very important: the ability to work in a virtual system, the analysis of prepared material and tracking of tasks to be assigned, participating in chats and discussion forums, virtual learning environments, audio and video conferences.

There is a big variety of approaches to distance learning and clarification of the concept. As Vermeersch states "distance learning is wellfounded relation by dialogue, structure and autonomy, which is necessary the technical mediatorial measures” (Vermeersch, 2008, p. 9). According to Rutkauskienè et al (2007) distance learning is the delivery form of knowledge, skills, attitudes, by applying ICT used by students to study in different places at the same time. Nuissl et al (2008) consider that distance learning is a form of learning when learners are physically separated from the teacher. Such separation can be applied to the whole learning process or through a mixed principle, for example, only some of the learning stages. Shachar and Neumann (2010) grounding on other researchers have researched the differences between traditional and distance learning and state that: "The transformation from the traditional Face-to-Face (FTF) classroom mode to new delivery methods and platforms (correspondence, Internetonline, one-way, two-way audio and video) collectively known as Distance Education (DE), led some experts so far as to predict that the 'residential based model,' that is, students attending classes at prearranged times and locations, will disappear in the near future” (Shachar and Neumann, 2010, p. 318).

Creation of a distance-learning course is based on the conceptual provisions of a dialogue, structure and autonomy. Dialogue is based on the humanist provision and students' interaction. We assume that success of learning implying improvement of students' reasoning, discussion, critical thinking skills is possible through active participation in dialogue. The interaction of the participants was based on the principle of structure in relation to detailed planning, a calendar systematic filling, time-fixing and control. As Rutkauskiene et al (2007) consider, the principle of autonomy encourages independent decision making, students' creative performance in a virtual learning environment.

\section{The course design and content}

The course was designed for part-time students who work or live far away from their educational institution. The creation of high quality content is essential if the potential of 'e-learning' is to be realised in a way that stimulates and fosters Lifelong Learning. "Certain features of online instruction are educationally advantageous, such as an increased opportunity for reflecting on and refining ideas, a greater degree of learner control over 
the materials, flexibility permitted by unrestricted access to the materials, and enhanced levels of interaction both in relation to the materials and in the opportunities presented for active learning by means of conferencing, discussion groups, and collaborative learning projects” (O’Lawrence, 2007).

With view to the ideas of students' autonomy, possibilities to reflect upon the study process and interact online, the design of the distance course was based on the symbiosis of theoretical and practical training. The structure of the course content and its components are presented in Figure 2.

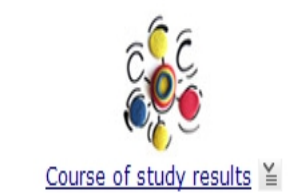

Course of study results

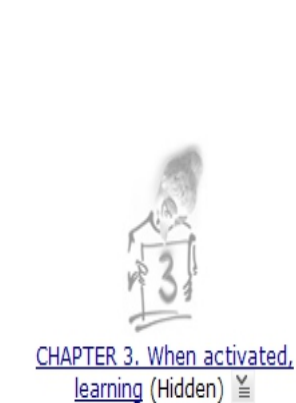

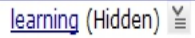

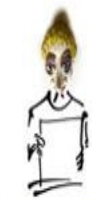

Introduction $\stackrel{v}{\equiv}$

Explains how to read the course content, how to learn.

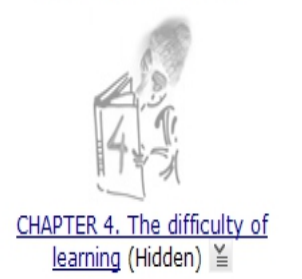

learning (Hidden) $\stackrel{\unrhd}{\equiv}$
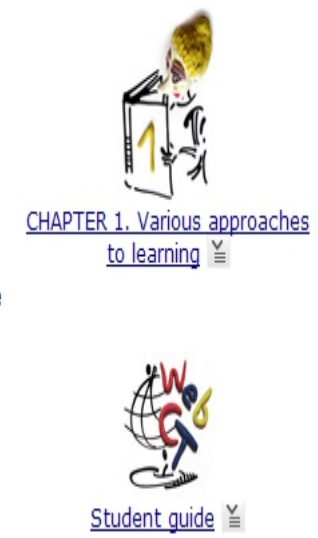

PDF file for printing
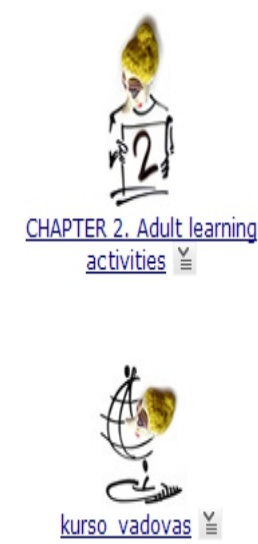

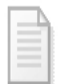

kuratoriaus vadovas (Hidden) $\cong$

Figure 3. Course content structure and the components

The Introduction chapter gave guidelines and course instructions on the analysis of new material, reflection of the texts, explanation of materials, acquisition techniques and ways of learning.

Theoretical issues were presented in four chapters (Different approaches to learning, Adult learning activities, Active-learning and Problem-based learning). The first section focusing on different approaches to learning based on various education theories revealed the essence of learning. The second chapter Adult learning activities described the forms of learning activities ranging from formal to informal learning in relation to life and experience and relevance of reflective learning and development of interpersonal skills was discussed. The third chapter was focused on active learning and the last one aimed at the issues of problem-based learning.

The Student guide was a reference section, where adult students could find answers to important questions. The guide also gave clues to the virtual distance learning environment: the main functions and characteristics 
of learning environment, allowing students to fully participate in learning process. The tools needed to review the course content, tasks, testing performance and interaction were also presented.

The general course objectives, expected student learning outcomes were outlined in the Student's guide. Besides the theoretical material, mind maps, practical exercises, funny pictures and graphics facilitated the learning process, visualised and graphically described the basic principles of learning. Visualisation of the course helped better understand the content and called to actively interact with symbols used in the texts. The interaction between the teacher and students was implemented by using virtual learning environment tools - discussion forums and e-mail.

Experience has shown that discussion forum is the most appropriate method to deal with various learning problems, as all students had a possibility to see the teachers' comments. It was identified that the evaluation system within this course not only verified the acquired theoretical knowledge, but also encouraged creative distance learning skills development.

\section{Findings on the quality of distance learning course}

In order to assess the relevance and quality of the course "Adult learning in distance studies" a quantitative survey was carried out. The integration of ICT into the learning process is important for learning process, and sometimes a determining factor in cultural, social and value terms. Furthermore, asynchronous learning online covers a broad spectrum of elearning methodologies (Vermeersch, et al, 2009), as for example, opportunities for interactivity with the programme. However, in distance course as argued by Jones (2004) resources available on computer, not technologies are in the focus of attention. All these factors should be taken into consideration and properly researched.

The findings evidence students' positive evaluation of the course material (86 per cent) stating that it was interesting (Figure 3). The majority of the course participants (80 per cent) considered the course material to be relevant. Another important feature of the course was absence of time constraints that positively influenced the learning process. The same number of the course participants (80 per cent) claimed that they had enough time for preparation of the course assignments and 15 per cent of the total sample expressed the opposite opinion (Figure 3).

The research findings disclosed that the course was arranged in a convenient format, materials logically and coherently presented.

Considering students' feedback the overall evaluation of the distance course was positive (Figures 3 and 4). 


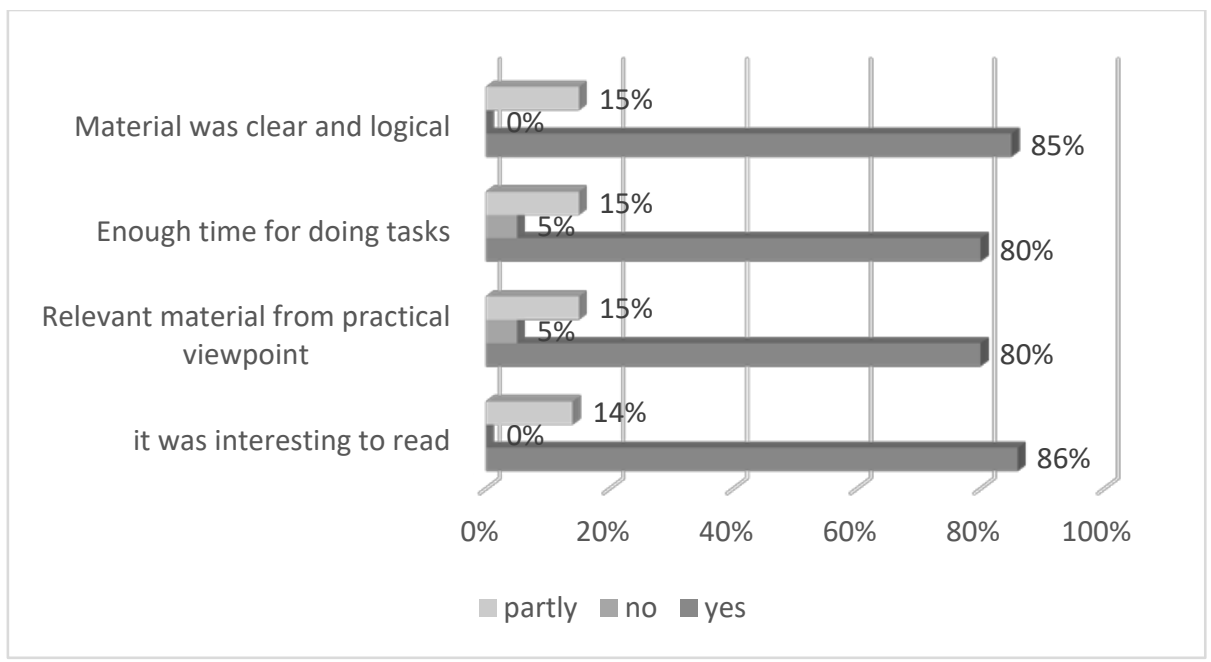

Figure 4. Evaluation of distance course

85 per cent of the respondents confirmed that material was presented in a comprehensible and logical manner (Figure 3), and the same per cent of students affirmed that the course content matched the course aims (Figure 4). 90 per cent of the surveyed respondents noted that the study subject was sufficiently illustrated by using visual animation. Visual and graphic design of the course helped students master the content and learn using creative skills (Figure 4). Besides the aspects mentioned above, most of the students acquired extra knowledge and skills of studying online (70 per cent). The majority of the course participants (75 per cent) would likely recommend this course to their colleagues (Figure 4).

Would you recommend this course to colleagues?

Do you think that you have acquired additional knowledge and skills about..

Course material sufficiently illustrated

Content suit of the course objectives

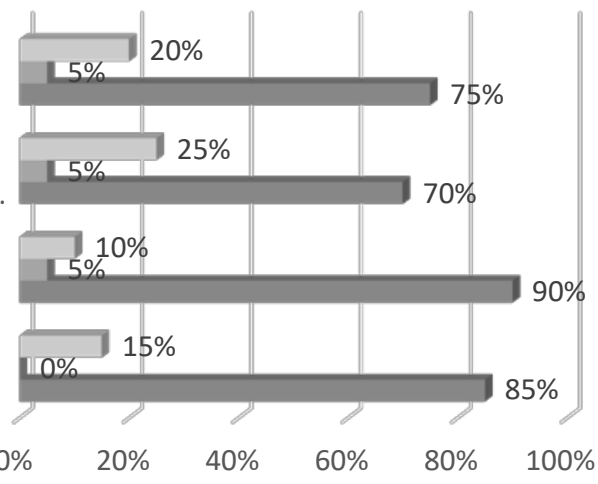

partly $\square$ no $\square$ yes

Figure 4. Assessment of distance learning course

The obtained results imply that technological environment and its resulting opportunities for learners to interact with each other and with 
teachers create favourable learning conditions. Moreover, opportunity to present detailed material builds preconditions for deep and meaningful learning.

Taking into account the changes in the society, labour market and education system distance courses are a necessity that can bring solutions to adult education development, especially to people living in remote locations or working professionals. The research proved that distance learning develops self-motivation, autonomous learning, social skills, such as communication and collaboration. Collaboration being a key element in natural democratic value attainment is a highly appreciated skill in modern society.

\section{Conclusion}

- $\quad$ Distance learning, as present day phenomenon is closely associated with advancement of new information technologies that are radically transforming the quality of life and have a significant impact on university studies. Distance learning is an effective learning tool and, therefore, a crucial factor to increase students' participation in studies. It is an imperative today to consider planning of studies, development of distance formal curriculum and flexible learning system in order to provide training services for adults, especially for residents in remote areas or working professionals.

- New technologies and their resulting opportunities for learners to interact with each other and with teachers, the ability to provide detailed material create preconditions for holistic learning in lifelong learning perspective.

- $\quad$ The case study of a distance course presented in this paper and survey findings revealed students' positive approach to distance learning course in the university educational process (86 per cent). The majority of the survey sample (80 per cent) found the course relevant and did not expererience any time constraints. This finding is particularly important when adult learning is discussed. The course material was engaging (75 per cent) as well as encouraging students' creative skills (70 per cent). The research proved that distance learning develops self-motivation, autonomous learning, social skills, such as communication and collaboration. Therefore, we assume that development of distance learning courses, constructivist learning environment with its inherent creative approach to learning provision can bring solutions to many social and educational issues, such as big emigration flows of young population, better employment opportunities and selfrealisation of young adults. 


\section{References:}

1. European Commission. (2006). Action plan for Adult Learning: It is always a good time to learn. Communication from the Commission to the Council, the European Parliament, the European Economic and Social Committee and the Committee of the Regions. Brussels.

2. European Commision. (2000). A Memorandum on Lifelong Learning. Brussels.

3. European Commision. Press Release Database. Retrieved from: http://europa.eu/rapid/press-release_IP-91-536_en.htm?locale=en.

4. European Council. (2001). Lisbon Strategy, 23 and 24 March 2000, Presidency Conclusions. Retrieved from: http://www.europarl.europa.eu/summits/lis1_en.htm

5. Fenwick, T. (2003). Learning through Experience: Troubling Orthodoxies and Intersecting Question. Malabar, FL: Krieger.

6. Jones, Ch. (2004). Network and learning: communities, practices and the metaphor of networks. ALT-J:Research in Learning Technology, 12 (1), pp. 81-93.

7. Honeyman, M., Miller, G. (1993). Agriculture distance education: A valid alternative for higher education? Proceedings of the National Agricultural Education Research Meeting, pp. 67-73.

8. Nuissl, E., Lattke, S. (2008). Qualifying adult learning professionals in Europe. Bielefeld: W. Bertelsmann Verlag.

9. O’Lawrence, H. (2007). An Overview of the Influences of Distance Learning on Adult Learners. Journal of Education and Human Development. 1 (1).

10. Rikala, J. (2015). Designing a Mobile Learning Framework for a Formal Educational Context. Finland: University of Jyvaskyla.

11. Rutkauskienè, D., Lenkevičius, A., Targamadzè, A., Volungevičienė, A., et al. (2007). Nuotolinio mokymosi desstytojo vadovas. Coursebook. Kaunas: Technologija.

12. Shachar, M. Neumann, Y. (2010). Twenty Years of Research on the Academic Performance Differences Between Traditional and Distance Learning: Summative Meta-Analysis and Trend Examination. MERLOT Journal of Online Learning and Teaching, 6 (2), June 2010, pp. 318-334.

13. Teresevičienė, M., Oldroyd, D., Gedvilienè, G. (2004). Suaugusiuju mokymasis. Andragogikos didaktikos pagrindai. Coursebook. Kaunas: VDU.

14. The Elearning Action Plan. Designing Tomorrow's Education. (2001). European Commission, Brussels. Retrieved from: http:/www.iglortd.org/members/SWISSORE/oldocs.htm. 
15. Distance learning: who's doing it now? The Guardian. Retrieved from:

http://www.theguardian.com/education/datablog/2014/jan/30/distance -learning-higher-education-moocs

16. The International Association For Distance Learning (IADL). Retrieved from: http://www.iadl.org.uk/aboutus.htm

17. Vermeersch, J. (2008). Getting started with open and distance learning (ODL). Garant.

18. Vermeersch, J. et al. (2009). Teachers' Aids on Creating Content for Learning Environments (TACCLE) The E-Learning Handbook for Classroom teachers, ed. Hughes, J. Brussels. 